УДК 902

https://doi.org/10.24852/2587-6112.2020.5.169.173

\title{
ЯЗЫЧЕСКИЕ ТРАДИЦИИ МОРДВЫ-ТЕРЮХАН В УСЛОВИЯХ ХРИСТИАНСКОГО МИРА
}

\section{(C) 2020 г. К.Н. Втюрина, Е.В. Четвертаков}

В статье рассматриваются процессы, связанные с взаимодействием мордвы-терюхан с окружающим их русским христианским миром. Мордву-терюхан принято считать наиболее «обрусевшей» частью мордовской общности. Источники говорят о тесных контактах терюхан с русским населением с периода XIII-XIV вв. Несмотря на это, судя по данным археологии, мордва-терюхане сохранили свои языческие традиции вплоть до начала XX в.

Ключевые слова: археология, мордва-терюхане, нижегородская мордва, Нижегородская область, Старосельский терюханский могильник, процессы христианизации, язычество.

\section{PAGAN TRADITIONS OF MORDVA-TERYUHANES IN THE CONDITIONS OF THE CHRISTIAN WORLD}

\author{
K.N. Vtyurina, E.V. Chetvertakov
}

The paper discusses the processes associated with the interaction of the Mordva-Teryuhanes with the Russian Christian world around them. The Mordva-Teryuhanes is considered to be the most "Russified" part of the Mordovian community. According to sources, the Teryuhanes had close contacts with the Russian population from the period of the $13^{\text {th }}-14^{\text {th }}$ centuries. Despite this, according to archaeology, the Mordva-Teryuhanes had preserved their pagan traditions until the beginning of the $20^{\text {th }}$ century.

Keywords: archaeology, the Mordva-Teryuhanes, the Nizhny Novgorod Mordva, Nizhny Novgorod Oblast, Staroselsky Teryuhansky cemetery, christianization, paganism.

Терюшевской мордвой или терюханами именуют небольшую группу финского коренного населения Нижегородского уезда Нижегородской губернии, имеющую компактный ареал расселения с центром в Терюшевской волости с эпохи раннего Средневековья (современная территория Дальнеконстантиновского, частично Кстовского и Богородского районов Нижегородской области).

Один из первых исследователей мордвы-терюхан П.И. Мельников-Печерский в работе «Очерки мордвы» писал об исторических связях и совместной жизни русского и мордовского населения. Также стоит отметить, что большое место в своей работе он уделял процессу «обрусения» мордвытерюхан: «Из всех народов так называемого чудского или финского племени, обитающих в России, ни одно так не обрусело в настоящее время, как мордва, особенно же та часть её, которая живет в Нижегородском уезде и называется терюханами» (Мельников-Печерский, 1981, с. 19).

Описывая историю мордвы конца XVII - начала XVIII вв., П.И. Мельников указал основную причину обрусения. «Но более всего на обрусение мордвы и на обращение её в христианство подействовала правительственная мера, принятая в конце XVII столетия, согласно которой в деревнях мордовских стали селить русских, а также и мордву переселять в русские деревни. Этот способ был употребляем преимущественно в тех местах, где жили терюхане. Вся Терюшевская волость, населенная терюханами, а также Лысковская, населенная русскими, были пожалованы в 1690 году Арчиле, царю Имеретинскому... Его управители переселили множество русских из Лысковской волости в Терюшевскую и еще более мордвы из Терюшевской в Лысковскую. Посредством браков мордовское население слилось с русским, стало забывать свой язык или говорить каким-то особым языком, в котором чуть не наполовину слов было русских. Обрусение терюхан пошло так сильно, что даже остававшиеся в язычестве, при совершении религиозных обрядов, в молитвах и пениях, мешали русские слова с мордовскими и с именами своих божеств соединяли имена истинного Бога (например, Саваоф) и христианских святых» (Мельников-Печерский, 1981, c. 19-20).

Когда же начались первые интенсивные контакты русских с мордвой-терюханами? На страницах древнерусских летописей упоминается первое серьёзное столкновение русских с мордвой, произошедшее в 1228 г.: «Того же месяца в 14 день великий князь Юрий и Ярослав и Константиновичи Василько, Всеволод 
пошли на мордву, и Муромский князь Юрий Давидович. Войдя в землю мордовскую, Пургасову волость, пожгли жита и потравили и скот перебили. Пленников послали назад, а мордва вбежала в леса свои, в укрепления...» (Лаврентьевская летопись, 2020, л. 155 об.). В XIV в. при великом князе Константине Васильевиче осуществлялось заселение мордовских земель по берегам рек Волги, Оки и Кудьмы (Сорокин, 2014, с. 251). Однако письменные источники ничего не говорят нам о контактах другого рода, прежде всего об экономических взаимоотношениях. Здесь мы обратимся к данным археологии, которые указывают скорее на мирное сосуществование мордвы и русских.

Первые исследования о совместном проживании русских с терюханами провел археолог И.С. Аникин. По результатам проведенной разведки по верхнему течению р. Озерки было обнаружено 7 поселений на берегах ручья Пергалейка (правый приток р. Озерки) на территории д. Городище и в ее ближайших окрестностях. Расстояние между археологическими памятниками не превышает 1 км. Интерес для нас представляют селища Городище-4, 5, 6 и 7, так как найденный на них керамический материал (лепная керамика с шамотом и гончарная керамика с шамотом, характерные для мордвы, и гончарная сероглиняная керамика с примесью дресвы и песка, т. е. русская средневековая керамика XIII-XIV вв.) позволяет судить о межэтнических контактах на данной территории с эпохи Средневековья (Аникин, 2001, с. 18-19). И.С. Аникин отмечает признаки смешения русской и мордовской керамических традиций. Эти особенности керамики могут служить доказательством того, что на данных поселениях существовали довольно-таки продолжительные культурно-бытовые контакты. Все это указывает на совместное проживание мордвы-терюхан и русских в этом регионе.

Русское население, совместно проживающее с мордвой в районе д. Городище, могло быть частью большого коллектива, расселившегося в верховьях бассейна реки Сундовик. Согласно «Нижегородскому летописцу», закудьминская земля вдоль р. Сундовик была довольно плотно заселена русским христианским населением, по крайней мере к началу 1370-х гг. Так, летописец сообщает о продаже нижегородским князем Дмитрием Константиновичем шести сел за рекой Кудьмой, на реке Сундовик: «В том же время был в Нижнем
Новгороде гость Тарас Петрович, самый богатый из нижегородских гостей; он накупил себе множество пленных людей всякого звания, и кроме того купил у великого князя вотчину за рекою Кудьмою, на реке Сундовик, состоящую из шести сел: Салова, в котором была церковь Бориса и Глеба, Ряховскаго, Запруднаго, Залябчикова и Мухарок...» (Нижегородский летописец, 1886, с. 15-16). Упомянутое в «Нижегородском летописце» с. Салово находится примерно в 20 км к западу от деревни Городище, таким образом, русский мир плотно подошел к границам расселения терюхан, по крайне мере с северо-востока к 1370-м гг.

Стоит отметить, что проникновение христианства фиксируется нами в комплексах раскапываемого Старосельского терюханского могильника. Так, во время археологических раскопок в 2019 г под руководством Е.В.Четвертакова былозафиксировано вторичное женское средневековое погребение № 28 (рис. 1), в составе комплекса украшений которой был обнаружен нательный крест - четырехконечный равносторонний с крестообразным углубленным ковчежцем и треугольным завершением лопастей. Данная находка относится к типу III, 2 по Д.А. Беленькой (Беленькая, 1993, с. 17), который появляется с XIII в. Это единственный случай наличия в погребении атрибута христианской символики для мордовских могильников и говорит о довольно раннем проникновении христианства в среду терюхан.

Каких-то веских оснований утверждать о насильственном обрусении мордвы-терюхан в эпоху Средневековья нет. Однако мордватерюхане начали терять свою национальную культуру, попав в крепостную зависимость после передачи в вотчинное владение Терюшевской, Лысковской и Белогорской волостей Петром I имеретинскому царю Арчиле Вахтанговичу в начале XVIII в. (Беговаткин, 2017, с. 41-42; Малышев, Сорокин, 2019, c. 67). Также первые серьёзные гонения на языческие традиции связаны с терюшевским восстанием, произошедшим в 1743-1745 гг. После подавления данного восстания стала проводиться политика насильственного крещения мордвы-терюхан. Данный процесс впервые нашел отражение в ревизской сказке 1762 г., где терюхане впервые были записаны как под своими исконными именами, так и под благоприобретенными крестильными (например, «Шатреско Чинаев, по крещению Андрей Гаврилович») (Шмелев, 2019, с. 42). 
Однако, несмотря на вышеуказанные процессы, данные раскопок Старосельского терюханского могильника (Четвертаков, 2016; Четвертаков, 2017; Четвертаков, 2018) говорят о стойких языческих традициях терюханского населения с XIII в. вплоть до новейшего времени. Приведем ряд черт похоронного языческого обряда, которые это иллюстрируют:

- сохраняется традиционная ориентировка погребенных на северо-запад и север;

- погребальной инвентарь в большом количестве включает украшения, орудия труда, монеты, а также элементы погребального костюма (хвост, венец, сустуг, плетни);

- практика жертвоприношений домашней птицы и скота;

\section{ЛИТЕРАТУРА}

Аникин И.С. Комплекс средневековых археологических памятников у д. Городище // Нижегородские исследования по краеведению и археологии: сборник научных и методических трудов. Вып. $1 /$ Отв. ред. Е.А. Молев. Нижний Новгород: Нижегор. гуманитар. центр, 2001. С. 16-23.

Беговаткин А.А. Терюшевская мордва - взгляд в прошлое // Нижегородская мордва: история и культура / Под ред. Е. В. Четвертакова, О. В. Гальцева. Дальнее Константиново: РКДО Д.-Константиновского района, 2017. С. 40-54.

Беленькая Д.А. Медная пластика городов московской Руси (XIII-XV вв.) // КСИА. 1993. № 208. С. $11-19$.

Лаврентьевская летопись URL: http: //expositions.nlr.ru/LaurentianCodex/_Project/page_Show.php (дата обращения: 02.01.2020).

Мальшеев А.В., Сорокин А.А. Мордовский «пророк» и «волжский царь»: к вопросу об отношениях Кузьмы Алексеева и князя Г.А. Грузинского // Конфессиональные и этнические группы российских регионов в XIX-XXI вв. / под общ. ред. А.А. Сорокина. М.: Эдитус, 2019. С. 66-73.

Мельников-Печерский П.И. (Андрей Печерский). Очерки Мордвы. Саранск: Мордовское книжное издательство, 1981. 132 с.

Нижегородский летописец / под ред. А.С. Гациского. Нижний Новгород: Типография губернского правления, 1886. 144 с.

Сорокин A.A. Великий князь нижегородско-суздальский Константин Васильевич: заметки к политической биографии // Константин Николаевич Бестужев-Рюмин. 1829-1897. Памяти русского историка / Под ред. А.В. Любавина. Богородск: Вариант, 2014. С. 244-255.

Четвертаков Е.B. Отчет об археологической разведке на территории Дальнеконстантиновского и Краснобаковского районов Нижегородской области в 2016 году // Архив ИА РАН. Р-1. 151 с.

Четвертаков E.B. Отчет об археологических раскопках на могильнике Староселье 3 в Дальнеконстантиновском районе Нижегородской области в 2018 году // Архив ИА РАН. Р-1. 130 с.

Четвертаков E.B. Отчет об археологических раскопках на могильнике Староселье 3 в Дальнеконстантиновском районе Нижегородской области в 2017 году // Архив ИА РАН. Р-1. 129 с.

Шмелев С.Ю. Родословная семьи Тихановых из села Мигалиха: от язычества до наших дней // Поволжские финны на перекрестке эпох / Под ред. Е.В. Четвертакова. Нижний Новгород: Новая гуманистическая культура, 2019. С. 41-48.

\section{Информация об авторах:}

Втюрина Ксения Николаевна, Нижегородский государственный университет им. Лобачевского, ИМОМИ (г. Нижний Новгород, Россия); kvtyurina@inbox.ru

Четвертаков Евгений Валентинович, методист, Дальнеконстантиновский районный музей (г. Нижний Новгород, Россия); Tank_kuz@mail.ru 


\section{REFERENCES}

Anikin, I. S. 2001. In Molev, E. A. (ed.). Nizhegorodskie issledovaniia po kraevedeniiu i arkheologii (Nizhny Novgorod Studies on Local History and Archaeology). Nizhnii Novgorod: Nizhegorodskii Gumanitarnyi Tsentr Publ., 16-32 (in Russian).

Begovatkin, A. A. 2017. In Chetvertakov, E. V., Galtsev, O. V. (eds.). Nizhegorodskaya mordva: istoriia i kul'tura (Nizhny Novgorod Mordovians: History and Culture). Dalneye Konstantinovo: RKDO D.-Konstantinovskogo raiona Publ., 40-54 (in Russian).

Belen'kaya, D. A. 1993. In Kratkie soobshcheniia Instituta arkheologii (Brief Communications of the Institute of Archaeology) 208, 11-19 (in Russian).

Lavrent'evskaia letopis' (Laurentian Chronicle). URL: http: //expositions.nlr.ru/LaurentianCodex/_Project/ page_Show.php accessed: 02.01.2020) (in Russian).

Malyshev, A. V., Sorokin, A. A. 2019. In Sorokin, A. A. (ed.). Konfessional'nye i jetnicheskie gruppy rossijskih regionov $v$ XIX-XXI vv. (Confessional and Ethnic Groups of Russian Regions in the $19^{\text {th }}-21^{\text {st }} c c$.). Moscow: "Editus: Publ., 66-73 (in Russian).

Mel'nikov-Pecherskiy, P. I. (Andei Pecherskiy). 1981. Ocherki Mordvy (Essays on the Mordva). Saransk: "Mordovskoe knizhnoe izdatel'stvo" Publ. (in Russian).

Nizhegorodskiy letopisets. (Nizhny Novgorod chronicler). 1886. In Gatsisky, A. S. (ed.). Nizhny Novgorod: Tipografiya gubernskogo pravleniya Publ.”(in Russian).

Sorokin, A. A. 2014. In Lyubavin, A. V. (ed.). Konstantin Nikolaevich Bestuzhev-Pyumin. 1829-1897. Pamiati russkogo istorika (Konstantin Nikolaevich Bestuzhev-Ryumin. 1829-1897. In memory of the Russian Historian). Bogorodsk: "Variant" Publ., 244-255 (in Russian).

Chetvertakov, E. V. 2016. Otchet ob arkheologicheskikh razvedkakh na territorii Dal nekonstantinovskogo I Krasnobakovskogo rajonov Nizhegorodskoj oblasti v 2016 godu. (Report on Archaeological Exploration in the Territory of the Dalnekonstantinovsky and Krasnobakovsky Districts of the Nizhny Novgorod Oblast in 2016). Archive of the Institute of Archaeology of the Russian Academy of Sciences R-1 (in Russian).

Chetvertakov, E. V. 2017. Otchet ob arkheologicheskikh raskopkakh na mogil'nike Starosel'e $3 v$ Dal nekonstantinovskom rajone Nizhegorodskoj oblasti v 2017godu. (Report on Archaeological Excavations at Staroselie 3 burial ground in the Dalnekonstantinovsky District of the Nizhny Novgorod Oblast in 2017). Archive of the Institute of Archaeology of the Russian Academy of Sciences R-1 (in Russian).

Chetvertakov, E. V. 2018. Otchet ob arkheologicheskikh raskopkakh na mogil'nike Starosel'e $3 v$ Dal nekonstantinovskom rajone Nizhegorodskoj oblasti v 2018 godu. (Report on Archaeological Excavations at Staroselye 3 Burial Ground in the Dalnekonstantinovsky District of the Nizhny Novgorod Oblast in 2018). Archive of the Institute of Archaeology of the Russian Academy of Sciences R-1 (in Russian).

Shmelev, S. Yu. 2019. In Chetvertakov, E. V. (ed.) Povolzhskie finny na perekrestke epokh (The Volga Region Finns at the Crossroads of Ages). Nizhniy Novgorod: "Novaya gumanisticheskaya cultura" Publ., 41-48 (in Russian).

\section{About the Authors:}

Vtyurina Ksenia N. N. I. Lobachevsky State University of Nizhny Novgorod. Gagarin Ave., 23, Nizhny Novgorod, 603950, Russian Federation; kvtyurina@inbox.ru

Chetvertakov Eugeny V. Dalnekonstantinovsky District Museum. Sovetskaya St., 89, Nizhny Novgorod, 606310, Russian Federation; Tank_kuz@mail.ru 

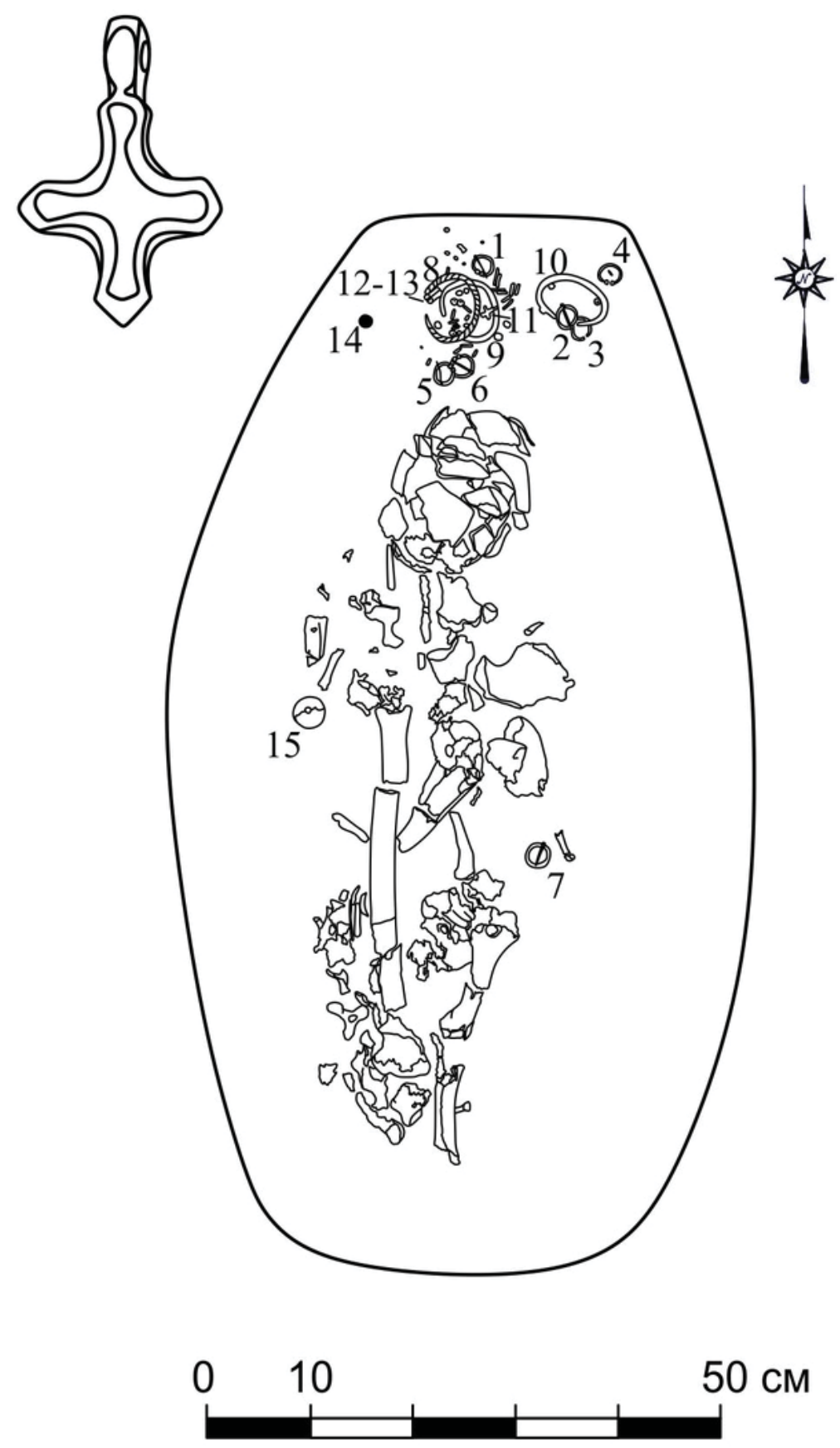

Рис. 1. Дальнеконстантиновский район. Могильник Староселье 3. Раскоп. Погребение №28 с бронзовым нательным крестом.

1-7 - застежки-фибулы бронзовые; 8-10 - браслеты бронзовые; 11 - крест бронзовый; 12, 13 - накладки бронзовые; 14 - бусина стеклянная; 15 - пряслице керамическое.

Fig. 1. Dalnekonstantinovsky district. Staroselye Burial Ground 3. Excavation. Burial №28 with a bronze cross. 1-7 - bronze fibula clasps; 8-10 - bronze bracelets; 11 - bronze cross; 12,13 - bronze overlays; 14 -glass bead; 15 ceramic spinning wheel. 